\title{
Gadolinium-Based Contrast Agents in Kidney Disease: A Comprehensive Review and Clinical Practice Guideline Issued by the Canadian Association of Radiologists
}

Canadian Journal of Kidney Health and Disease

Volume 5: I-I7

(C) The Author(s) 2018

Reprints and permissions:

sagepub.co.uk/journalsPermissions.nav DOI: 10.1 I77/2054358। I8778573 journals.sagepub.com/home/cjk (S)AGE

\author{
Nicola Schieda', Jason I. Blaichman ${ }^{2}$, Andreu F. Costa ${ }^{3}$, \\ Rafael Glikstein ${ }^{4,5}$, Casey Hurrell ${ }^{6}$ iD, Matthew James ${ }^{7,8}$, \\ Pejman Jabehdar Maralani ${ }^{9}$, Wael Shabana ${ }^{10}$, An Tang ${ }^{11,12}$, \\ Anne Tsampalieros ${ }^{13}$, Christian B. van der Pol ${ }^{14}$, \\ and Swapnil Hiremath ${ }^{15}$
}

\begin{abstract}
Purpose of review: Use of gadolinium-based contrast agents (GBCA) in renal impairment is controversial, with physician and patient apprehension in acute kidney injury (AKI), chronic kidney disease (CKD), and dialysis because of concerns regarding nephrogenic systemic fibrosis (NSF). The position that GBCA are absolutely contraindicated in AKI, category G4 and G5 CKD (estimated glomerular filtration rate $[e G F R]<30 \mathrm{~mL} / \mathrm{min} / 1.73 \mathrm{~m}^{2}$ ), and dialysis-dependent patients is outdated and may limit access to clinically necessary contrast-enhanced magnetic resonance imaging (MRI) examinations. This review and clinical practice guideline addresses the discrepancy between existing Canadian guidelines regarding use of GBCA in renal impairment and NSF.

Sources of information: Published literature (including clinical trials, retrospective cohort series, review articles, and case reports), online registries, and direct manufacturer databases were searched for reported cases of NSF by class and specific GBCA and exposed patient population.

Methods: A comprehensive review was conducted identifying cases of NSF and their association to class of GBCA, specific GBCA used, patient, and dose (when this information was available). Based on the available literature, consensus guidelines were developed by an expert panel of radiologists and nephrologists.

Key findings: In patients with category G2 or G3 CKD (eGFR $\geq 30$ and $<60 \mathrm{~mL} / \mathrm{min} / 1.73 \mathrm{~m}^{2}$ ), administration of standard doses of GBCA is safe and no additional precautions are necessary. In patients with AKI, with category G4 or G5 CKD $\left(\right.$ eGFR $\left.<30 \mathrm{~mL} / \mathrm{min} / 1.73 \mathrm{~m}^{2}\right)$ or on dialysis, administration of GBCA should be considered individually and alternative imaging modalities utilized whenever possible. If GBCA are necessary, newer GBCA may be administered with patient consent obtained by a physician (or their delegate) citing an exceedingly low risk (much less than I\%) of developing NSF. Standard GBCA dosing should be used; half or quarter dosing is not recommended and repeat injections should be avoided. Dialysisdependent patients should receive dialysis; however, initiating dialysis or switching from peritoneal to hemodialysis to reduce the risk of NSF is unproven. Use of a macrocyclic ionic instead of macrocyclic nonionic GBCA or macrocyclic instead of newer linear GBCA to further prevent NSF is unproven. Gadopentetate dimeglumine, gadodiamide, and gadoversetamide remain absolutely contraindicated in patients with AKI, those with category G4 or G5 CKD, or those on dialysis. The panel agreed that screening for renal disease is important but less critical when using macrocyclic and newer linear GBCA. Monitoring for and reporting of potential cases of NSF in patients with AKI or CKD who have received GBCA is recommended.

Limitations: Limited available literature (number of injections and use in renal impairment) regarding the use of gadoxetate disodium. Limited, but growing and generally high-quality, number of clinical trials evaluating GBCA administration in renal impairment. Limited data regarding the topic of Gadolinium deposition in the brain, particularly as it related to patients with renal impairment.

Implications: In patients with AKI and category G4 and G5 CKD (eGFR $\left.<30 \mathrm{~mL} / \mathrm{min} / \mathrm{I} .73 \mathrm{~m}^{2}\right)$ and in dialysis-dependent patients who require GBCA-enhanced MRI, GBCA can be administered with exceedingly low risk of causing NSF when using macrocyclic agents and newer linear agents at routine doses.
\end{abstract}




\begin{abstract}
Abrégé
Objectif de la revue: L'utilisation d'agents de contraste à base de gadolinium (ACBG) est controversée dans les cas d'insuffisance rénale. En effet, en raison de préoccupations concernant la fibrose systémique néphrogénique (FSN), elle suscite l'appréhension des médecins et des patients dans les cas d'insuffisance rénale aiguë (IRA), d'insuffisance rénale chronique (IRC) et chez les patients dépendants de la dialyse. La perception selon laquelle les ACBG seraient formellement contre-indiqués dans les cas d'IRA, d'IRC de stade G4 et G5 (débit de filtration glomérulaire estimé [DFGe] $<30 \mathrm{ml} / \mathrm{min} / \mathrm{I}, 73$ $\mathrm{m}^{2}$ ) et de dépendance à la dialyse est obsolète et pourrait limiter l'accès à l'IRM rehaussée par contraste - un examen cliniquement nécessaire. La présente revue et les directives cliniques proposées portent sur les incohérences des lignes directrices canadiennes actuelles en regard de l'utilisation des ACBG dans les cas d'insuffisance rénale et de FSN.

Sources: Nous avons répertorié les cas déclarés de FSN selon l'ACBG utilisé (et sa classe) et selon les populations exposées, dans les articles publiés (essais cliniques, études de cohorte rétrospectives et rapports de cas), les registres en ligne et les bases de données des fabricants.

Méthodologie: Nous avons procédé à un examen approfondi des sources pour répertorier les cas de FSN et leur association à une classe d'ACBG, à un $A C B G$ en particulier, à la situation du patient et à la dose administrée (lorsque l'information était disponible). Un comité d'experts (néphrologues et radiologues) a émis de nouvelles lignes directrices consensuelles conformes aux résultats obtenus.

Principaux résultats: Chez les patients atteints d'IRC de stade $G 2$ ou G3 (DFGe $\geq 30$ et $<60 \mathrm{ml} / \mathrm{min} / \mathrm{l}, 73 \mathrm{~m}^{2}$ ), l'administration d'ACBG aux doses habituelles est bénigne et aucune précaution n'est nécessaire. Lorsque possible, l'administration d'ACBG devrait faire l'objet d'une évaluation au cas par cas et d'autres modalités d'imagerie devraient être envisagées dans les cas d'IRA, d'IRC de stade G4 ou G5 ou de dépendance à la dialyse. Si le recours aux ACBG est nécessaire, on peut se tourner vers de nouvelles classes d'ACBG à risque excessivement faible (moins de I \%) d'occasionner une FSN, tant que le médecin (ou son délégué) obtient le consentement du patient. On emploiera les doses d'ACBG habituelles; il n'est pas recommandé d'administrer de doses réduites, et les injections répétées devraient être évitées. Les patients dépendants de la dialyse devraient poursuivre leur traitement. On notera qu'il n'existe aucune preuve que l'initiation d'un traitement de dialyse ou que la transition de la dialyse péritonéale à l'hémodialyse réduise les risques de FSN. Le recours à des ACBG macrocycliques ioniques plutôt que non ioniques, ou à des $A C B G$ macrocycliques plutôt qu'aux plus récents $A C B G$ linéaires, n'a pas été démontré plus efficace pour prévenir la FSN. Par ailleurs, le gadopentétate de diméglumine, le gadodiamide et le gadoversétamide demeurent formellement contre-indiqués dans les cas d'IRA, d'IRC de stade G4 ou G5, et de dépendance à la dialyse. Le comité d'experts a convenu que le dépistage de l'insuffisance rénale, quoiqu'important, s'avère secondaire lors de l'administration des plus récents ACBG linéaires ou d'ACBG macrocycliques. La déclaration et le suivi des possibles cas de FSN liés à l'utilisation des $A C B G$ chez les patients atteints d'IRA ou d'IRC sont recommandés.

Limites: Plusieurs facteurs limitent la portée de nos résultats : i) la quantité limitée d'articles portant sur l'utilisation du gadoxétate disodique (notamment sur le nombre d'injections et son utilisation dans les cas d'insuffisance rénale); ii) le nombre limité (quoique croissant et généralement de grande qualité) d'essais cliniques évaluant l'administration des ACBG en contexte d'insuffisance rénale et; iii) la quantité limitée de données concernant l'accumulation du gadolinium dans le cerveau, particulièrement chez les patients atteints d'insuffisance rénale.
\end{abstract}

\footnotetext{
'Department of Medical Imaging, The Ottawa Hospital, University of Ottawa, Ontario, Canada

${ }^{2}$ Faculty of Medicine, Department of Radiology, University of British Columbia, Vancouver, Canada

${ }^{3}$ Department of Diagnostic Radiology, Queen Elizabeth II Health Sciences Centre, Dalhousie University, Halifax, Nova Scotia, Canada

${ }^{4}$ Brain and Mind Research Institute, Ottawa Hospital Research Institute, University of Ottawa, Ontario, Canada

${ }^{5}$ Neuroradiology Section, MRI Modality Lead, Department of Medical Imaging, The Ottawa Hospital, University of Ottawa, Ontario, Canada

${ }^{6}$ Canadian Association of Radiologists, Ottawa, Ontario, Canada

${ }^{7}$ Cumming School of Medicine, University of Calgary, Alberta, Canada

${ }^{8}$ Department of Community Health Sciences, University of Calgary, Alberta, Canada

${ }^{9}$ Department of Medical Imaging, University of Toronto, Ontario, Canada

${ }^{10}$ Department of Medical Imaging, The Ottawa Hospital, University of Ottawa, Ontario, Canada

"Department of Radiology, Radio-oncology and Nuclear Medicine, University of Montreal, Québec, Canada

${ }^{12}$ Centre de recherche du Centre Hospitalier de l'Université de Montréal, Québec, Canada

${ }^{13}$ Division of Nephrology, Children's Hospital of Eastern Ontario, Clinical Epidemiology Program and the University of Ottawa, Ontario, Canada

${ }^{14}$ Department of Radiology, Brigham and Women's Hospital, Harvard University, Boston, MA, USA

${ }^{15}$ Division of Nephrology, Department of Medicine and Kidney Research Centre, Ottawa Hospital Research Institute, University of Ottawa, Ontario, Canada
}

Corresponding Author:

Nicola Schieda, 1053 Carling Avenue, CI, Ottawa, Ontario, Canada KIY 4E9.

Email: nschieda@toh.on.ca 
Conclusion: Lorsque des examens d'IRM rehaussés par contraste sont nécessaires, les plus récents ACBG linéaires et les ACBG macrocycliques peuvent être administrés aux doses habituelles avec un risque excessivement faible de causer une FSN chez les patients atteints d'IRA, d'IRC de stade G4 et G5 (DFGe $<30 \mathrm{ml} / \mathrm{min} / \mathrm{l}, 73 \mathrm{~m}^{2}$ ), de même que chez les patients dépendants de la dialyse.

\section{Keywords}

magnetic resonance imaging, gadolinium, nephrogenic systemic fibrosis, NSF, guideline

Received January 23, 20I8. Accepted for publication March 3I, 2018.

\section{What was known before}

NSF is strongly associated with administration of GBCA in patients with category G4 or G5 CKD or on dialysis. Avoidance of GBCA in patients with renal impairment may be unnecessary due to important differences in incidence of NSF with macrocyclic and newer linear GBCA.

\section{What this adds}

This guideline acknowledges that NSF is exceedingly uncommon when macrocyclic or newer linear GBCA are used in patients with category G4 or G5 CKD improves access to GBCA-enhanced MRI when medically necessary and in immediate and anticipated reductions in outpatient screening of renal function prior to GBCA-enhanced MRI.

\section{Introduction}

Gadolinium-based contrast agents (GBCA) have been in clinical use for decades and have an integral role in magnetic resonance imaging (MRI) examinations. In general, GBCA have an excellent safety profile ${ }^{1-7}$; however, they have been identified as the causative agent in nephrogenic systemic fibrosis (NSF). ${ }^{8}$ Due to the associations between NSF in patients receiving GBCA and renal impairment, the use of GBCA has been considered absolutely contraindicated in patients with acute kidney injury (AKI) and severe chronic kidney disease (CKD) and in those receiving dialysis. ${ }^{9-11}$ Nevertheless, the vast majority of documented NSF cases have occurred in patients who received linear nonionic or older linear ionic GBCA (often repeatedly and/or at higherthan-recommended dosage). ${ }^{12}$ The incidence of NSF has substantially decreased over the past several years, and this is attributed mainly to physician awareness and avoidance of GBCA in at-risk patients, the use of newer macrocyclic and linear ionic GBCA, and avoiding repeat injections and greater than recommended dosing. ${ }^{2-14}$ In Canada, for example, to our knowledge the last officially documented case of NSF occurred in a 70-year-old patient who received an unspecified GBCA in 2011. ${ }^{15}$

To address a disparity in Canadian guidelines regarding NSF and more recent literature evaluating NSF in macrocyclic and newer linear ionic agents, updated guidelines were developed by a joint working group involving members of the Canadian Association of Radiology (CAR) and the Canadian Society of Nephrology (CSN). The goals of the working group were to review the literature regarding the NSF safety profile of GBCAs that are currently approved for clinical use in Canada and to recommend clinical practice guidelines for physicians when considering the use of GBCA in at-risk patients, namely those with AKI, stage G4 or G5 $\mathrm{CKD}$, or on dialysis (herein referred to simply as "at-risk" patients); see Appendix A. The purpose of these guidelines was not to exhaustively review the mechanisms of NSF, or the biochemistry of gadolinium chelates in general, or to address the recently-described phenomenon of gadolinium deposition in the brain (which is being reviewed with guidelines formulated by a separate working group commissioned by the CAR); however, these concepts were considered and are addressed briefly herein. Data on the risk of GBCA allergic adverse events are not reviewed and are beyond the scope of this guideline but have been described elsewhere. ${ }^{16}$

\section{Background}

GBCAs have been used in conjunction with MRI since the 1980s and have an overall excellent cumulative safety record. ${ }^{17,18}$ The ideal GBCA has high relaxivity (to generate increased contrast on T1-weighted magnetic resonance images), would require a low, nontoxic dose, and is welltolerated without any adverse immediate or long-term effects. GBCAs are derived and administered in a chelated form to minimize the amount of free gadolinium in the body. ${ }^{17-19}$ GBCAs used clinically should have high stability to prevent dissociation of gadolinium and should be rapidly cleared and excreted from the body. ${ }^{17,18}$ The stability of GBCAs depends on their chemical structure; GBCAs can be classified as (1) either linear or cyclic (note that GBCAs with a cyclic chelating ligand are commonly referred to as macrocyclic) and (2) electrically neutral (nonionic) or charged (ionic). Although the overall stability of a given GBCA is unique for each molecular structure and other factors that may influence stability that are beyond the scope of this article, ${ }^{17}$ in general a macrocyclic structure confers greater stability than a linear structure, and to a lesser extent, ionic GBCAs have greater stability than nonionic structure. ${ }^{17-19}$ The rapidity of the clearance of GBCAs from the body is another key determinant of patient safety as the extended presence of 
GBCAs (due to delayed clearance) within the body increases the risk of release of dissociated free gadolinium ions. ${ }^{17}$ All but one GBCA (ie, gadoxetic acid) are excreted almost exclusively by the kidneys: renal function is critical when considering risk of NSF.

NSF is a serious late adverse reaction associated with exposure to GBCAs that can occur in patients with severe renal impairment and for which there is currently no known specific or consistently effective treatment. ${ }^{12,18-21}$ Although the association between exposure to GBCAs and development of NSF is widely accepted, the mechanism is incompletely understood. ${ }^{12,18}$ The risk factors for NSF can be divided into patient-related factors and those related to the molecular structure and stability of the GBCA used. Based on current evidence, NSF occurs almost exclusively in patients receiving GBCAs who have category G4 (severe decrease in estimated glomerular filtration rate [eGFR], with or without other evidence of kidney damage; eGFR 15-29 $\mathrm{mL} / \mathrm{min} / 1.73 \mathrm{~m}^{2}$ ) or category G5 (established renal failure eGFR $<15 \mathrm{~mL} / \mathrm{min} / 1.73 \mathrm{~m}^{2}$ or on dialysis) CKD based on the Kidney Disease Outcomes Quality Initiative (KDOQI) from the National Kidney Foundation. ${ }^{22}$ Therefore, severely reduced renal function is the most important patient-related risk factor predisposing to NSF. ${ }^{12,18,19,23}$ The degree of renal insufficiency is also important, with a much greater incidence of NSF in patients with category G5 CKD compared with category G4 CKD. Acute kidney injury is also considered a risk factor for NSF. ${ }^{12,19}$ A proinflammatory state in a patient with impaired renal function has also been reported as a risk factor. ${ }^{12,19,24,25}$ Despite initial concerns, severe liver disease is no longer considered a risk factor for NSF, as long as the patient has normal renal function. ${ }^{12,18,19,26-28}$ Because of renal immaturity in fetuses, neonates, and infants, this population (and consequently pregnant women because of the risk to the fetus) is considered potentially at risk. ${ }^{12,18,19,29,30}$ Regardless of the type of GBCA used, higher doses and multiple administrations, especially within a short period of time, have been reported as risk factors for the development of NSF.

Risk for NSF is also generally considered to be related to the molecular structure and stability of the GBCA used. The majority of unconfounded cases of NSF that have been reported are associated with 3 GBCAs: gadodiamide, gadopentetate dimeglumine, and gadoversetamide (see Table 1 and subsequent sections for a description of different GBCAs currently used clinically). ${ }^{19,31-33}$

The incidence of NSF using newer linear and macrocyclic agents has decreased considerably. It is difficult to accurately estimate the prevalence of NSF, but it is now considered a rare entity. Reported incidences of NSF vary but when using standard dosing and macrocyclic or newer linear GBCAs are generally cited to be much less than $1 \%$ (with the denominator being administration to all patients); however, this may underestimate the true prevalence of disease given that for a time GBCA was avoided nearly universally in at-risk populations. ${ }^{12,18,19,33}$ For example, in at-risk populations, the prevalence can be much higher, between $3 \%$ and $7 \%$ for older linear GBCAs but remains case reportable for the newer linear and macrocyclic GBCAs. ${ }^{18,31}$ A discussion of criteria for the diagnosis of NSF, reporting bias or underreporting of NSF, and unconfounded versus confounded cases is beyond the scope of this article but has been described elsewhere. ${ }^{18,19,34}$

There is a long-standing recognition that gadolinium can replace calcium in the hydroxyapatite of bone ${ }^{19}$ and more recently, there are increasing concerns about GBCA deposition in the brain. ${ }^{35-37}$ This is the topic of a separate CAR working group on GBCA use and safety and will not be further discussed here.

\section{Currently Approved GBCA for Clinical Use in Canada}

There are presently 8 GBCA approved for clinical use in Canada $^{9}$; these are summarized in Figure 1 and Table 1. The following section describes these agents in detail as they pertain to risk of NSF. Following published literature, "unconfounded" cases refer to the occurrence of NSF with prior exposure to only one GBCA; "confounded" cases refer to cases where more than one GBCA was administered, and hence causality is difficult to assign. The GBCAs are divided into 3 classes: (1) older linear agents associated with the highest number of unconfounded cases of NSF (gadodiamide, gadopentetate dimeglumine, and gadoversetamide), (2) newer linear agents associated with zero unconfounded cases of NSF (gadobenate dimeglumine and gadoxetate disodium), and (3) macrocyclic agents associated with an exceedingly low number of unconfounded cases of NSF. The American College of Radiology (ACR) manual on contrast media v 10.3 classifies the older linear GBCAs as class I, macrocyclic agents and gadobenate dimeglumine as class II, and considers gadoxetate disodium as a class III agent separate from gadobenate dimeglumine (due to limited data regarding NSF risk ${ }^{38}$ ); however, in this document the panel suggested that gadoxetate disodium and gadobenate dimeglumine be considered together due to similar structure and number of NSF cases reported to date.

\section{Older Linear Agents Associated With the Greatest Number of Unconfounded Cases of NSF}

Gadodiamide, gadopentetic acid, and gadoversetamide. Gadodiamide, marketed by GE Healthcare (Chicago, Illinois) as Omniscan, a linear nonionic GBCA (thermodynamic stability of 16.9), gadopentetic acid, marketed as Magnevist by Bayer Healthcare Pharmaceuticals (Berlin, Germany), a linear ionic GBCA (thermodynamic stability of 22.5), and to a lesser extent gadoversetamide, marketed as Optimark by Guerbet (Villepinte, France), a linear nonionic GBCA (thermodynamic stability of 16.6) are by far the most common GBCA associated 


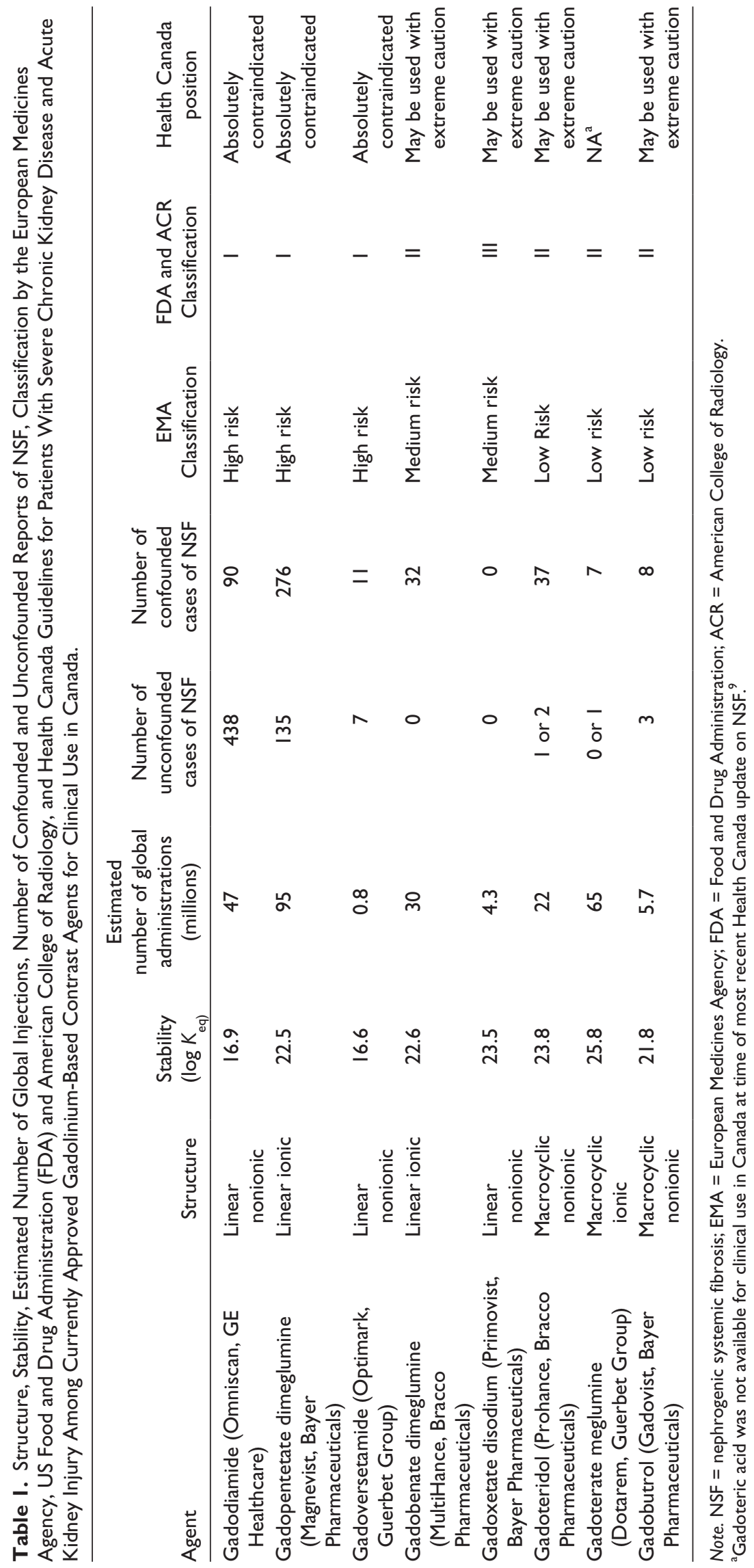




\begin{tabular}{|c|c|c|}
\hline & Cyclic & Linear \\
\hline \multirow{3}{*}{ Ionic } & \multirow{3}{*}{$\begin{array}{c}\text { Gd-DOTA } \\
\text { gadoterate meglumine } \\
\text { Dotarem }^{\odot}\end{array}$} & $\begin{array}{c}\text { Gd-DTPA } \\
\text { gadopentetate dimeglumine } \\
\text { Magnevist }^{\circ}\end{array}$ \\
\hline & & $\begin{array}{c}\text { Gd-BOPTA } \\
\text { gadobenate dimeglumine }^{\text {MultiHance }}{ }^{\ominus}\end{array}$ \\
\hline & & $\begin{array}{c}\text { Gd-EOB-DTPA } \\
\text { gadoxetic acid disodium salt } \\
\text { Primovist }^{\odot}\end{array}$ \\
\hline \multirow{2}{*}{ Non-ionic } & $\begin{array}{l}\text { Gd-BT-DO3A } \\
\text { gadobutrol } \\
\text { Gadovist }^{\circ}\end{array}$ & $\begin{array}{l}\text { Gd-DTPA-BMEA } \\
\text { gadoversetamide } \\
\text { OptiMARK }\end{array}$ \\
\hline & $\begin{array}{l}\text { Gd-HP-DO3A } \\
\text { gadoteridol } \\
\text { ProHance }\end{array}$ & $\begin{array}{l}\text { Gd-DTPA-BMA } \\
\text { gadodiamide } \\
\text { Omniscan }^{\odot}\end{array}$ \\
\hline
\end{tabular}

Figure I. Depiction of the current gadolinium-based contrast agents approved for clinical use in Canada.

with reported cases of NSF. ${ }^{12}$ At the time of preparation of this document, 438 unconfounded cases of NSF have been attributed to gadodiamide, 135 unconfounded cases of NSF have been attributed to gadopentetic acid, and 7 unconfounded cases of NSF attributed to gadoversetamide. ${ }^{12}$ By comparison to macrocyclic and newer linear agents, these 3 agents constitute the vast majority of reported cases of NSF. In cases of NSF confounded by the use of multiple agents, when 1 of these 3 agents had been administered (90 confounded cases of NSF with gadodiamide, 276 confounded cases with gadopentetic acid and 11 confounded cases with gadoversetamide ${ }^{12}$ ), it is generally assumed that 1 of these agents was likely the causative GBCA which led to the development of disease, although it is not possible to prove which agent was ultimately responsible for causing NSF when multiple agents had been administered to the same patient. These agents are considered as high risk for causing NSF in at-risk populations by the European Medicines Agency $^{11}$ and categorized as Class I agents by the American College of Radiology Manual on Contrast Media v 10.3 (agents associated with the greatest number of NSF cases). ${ }^{38}$ The use of any of these 3 agents in patients with AKI, on dialysis, or with severe CKD continues to be considered absolutely contraindicated by the US Food and Drug Administration (FDA), ${ }^{10}$ European Medicines Agency,${ }^{11}$ and Health Canada. ${ }^{9}$ The panel does not recommend using gadodiamide, gadopentetic acid, or gadoversetamide in at-risk patients under any circumstances and could not conceive of an instance when an MRI facility in Canada could not obtain an alternative macrocyclic or newer linear GBCA even with single vendor contrast agreements where in our opinion exemptions should be granted.

\section{Newer Linear Agents Associated With Zero Unconfounded Cases of NSF}

Gadobenate dimeglumine. Gadobenate dimeglumine, marketed as MultiHance by Bracco Pharmaceuticals (Milan, Italy), is a linear, ionic contrast agent. ${ }^{39}$ It has been marketed in Canada since 2004, after receiving approval from Health Canada ${ }^{40}$ and is classified as a group II medical imaging agent by the FDA (approved in 2004) ${ }^{41}$ and by the ACR. ${ }^{42}$ The distribution of gadobenate dimeglumine is extracellular and its clearance is mostly renal $(96 \%) .{ }^{39}$ The biliary elimination pathway (4\%) provides limited protection for patients with CKD. Gadobenate dimeglumine has a thermodynamic stability constant of 22.6. ${ }^{39}$

According to a literature review performed by Bracco Pharmaceuticals, as of 31 October 2016, there are no medically confirmed, unconfounded cases of NSF following the sole administration of gadobenate dimeglumine. This document reports 32 confounded cases of NSF that arose following the administration of MultiHance and other GBCA, most often gadodiamide and gadopentetate dimeglumine. 
There are no known confounded cases of NSF where a patient received only gadobenate dimeglumine and gadoteridol in combination. ${ }^{43}$ A summary of important studies evaluating NSF and gadobenate dimeglumine is provided in Appendix B.

Gadoxetate disodium. Gadoxetate disodium (marketed as Primovist in Europe and Canada and Eovist in the United States; Bayer Pharmaceuticals) is a linear ionic $\mathrm{GBCA}^{39}$ distributed in Canada since 2010, after receiving approval from Health Canada. ${ }^{40}$ The FDA approved it in $2008^{44}$ and $\mathrm{ACR}^{42}$ classifies it as a group III agent. The thermodynamic stability constant of gadoxetate disodium is 23.5 (37). Gadoxetate disodium has a dual-elimination pathway split evenly between renal $(50 \%)$ and hepatobiliary $(50 \%)$ pathways. ${ }^{39}$ The extrarenal clearance could theoretically reduce the risk of NSF in patients with CKD, assuming normal liver function; however, empiric data are scant. Another potentially protective feature of gadoxetate disodium is the lower gadolinium dose, which is $25 \%$ that of other GBCAs at 0.025 $\mathrm{mmol} / \mathrm{kg}$, because a large proportion of NSF cases involved higher doses or repeated GBCA injections (see, for example, Zou and Ma, ${ }^{45}$ where 245 out of 280 patients who developed NSF with other GBCAs had received a higher than standard $\operatorname{dose}^{45}$ ); however, this is also unproven.

The number of studies assessing the safety of gadoxetate disodium is very limited. In a 2009-2013 prospective multicenter study, in renally impaired patients scheduled for a liver imaging examination, Lauenstein et al reported no NSF events in 85 patients with category G4 or G5 CKD, including 39 on dialysis, who received gadoxetate disodium at full dose $(0.025 \mathrm{mmol} / \mathrm{kg}){ }^{46}$ The same study reported no NSF events in 193 patients with nondialysis category G3 CKD who received gadoxetate disodium at full dose. ${ }^{46}$ In a 20112013 retrospective study, Song et al evaluated 40 patients at risk for NSF who underwent 2 liver MRI studies within a 6-month interval, using full and half doses of gadoxetate disodium; the eGFR at the time of the half-dose MRI ranged between 4.8 and $58.5 \mathrm{~mL} / \mathrm{min} / \mathrm{m}^{2}$. With the half-dose MRI, there was reduced hepatic enhancement in all but the arterial phase; however, there was no difference in diagnostic quality between the 2 doses or in any cases of NSF. ${ }^{47}$

While no unconfounded or confounded cases of NSF have been reported using gadoxetate disodium, a limitation to evaluating its safety profile with respect to NSF is that, as a newer agent with specific indications, there have been substantially fewer injections of gadoxetate disodium as compared with other GBCAs. The use of gadoxetate disodium in clinical practice is generally restricted to the assessment of colorectal cancer liver metastases (CRCLM), differentiating hepatic focal nodular hyperplasia (FNH) from hepatocellular adenoma (HCA), and evaluating for biliary leaks. CRCLM detection is particularly crucial for surgical planning (ie, metastasectomy), and although alternative studies (contrastenhanced computed tomography [CT] and positron emission tomography [PET]) are available, there is a higher detection rate using gadoxetate disodium-enhanced MRI compared with both CT and PET. ${ }^{48,49}$ Gadoxetate disodium-enhanced MRI is also more accurate when compared with conventional MRI and CT for confirmation of radiologic complete response of liver metastases ("disappearing metastases"). ${ }^{50}$ The usefulness of gadoxetate disodium for diagnosis of FNH versus HCA has recently been found to be less than previously reported, ${ }^{51}$ and the patient population for which these diagnoses are considered are generally young healthy female patients where AKI or severe renal impairment is not anticipated. Therefore, a clinical situation where gadoxetate disodium is required to evaluate for FNH versus HCA in AKI or severe renal impairment is unlikely. The use of gadoxetate disodium in cirrhotic patients for diagnosis of hepatocellular carcinoma is under active investigation and not currently considered the reference standard (compared with extracellular GBCAs). ${ }^{52}$

\section{Macrocyclic Agents Associated With an Exceedingly Low Number of Unconfounded Cases of NSF}

Gadoterate meglumine. Gadoterate meglumine, marketed as Dotarem by Guerbet Pharmaceuticals (Villepinte, France) is a macrocyclic, ionic agent. ${ }^{53,54}$ This agent was approved by Health Canada in $2016^{40}$ but has been in clinical use in Europe for many years. It is classified as a group II agent by the FDA, who approved it in $2013^{55}$ and by the ACR. ${ }^{42}$ Its distribution is extracellular, and its clearance is entirely renal. $^{39}$ The thermodynamic stability constant is $25.6^{39}$ Gadoterate meglumine has the highest thermodynamic stability of all the GBCAs, and it has been suggested that its structure may make it safer for use in patients at risk for $\mathrm{NSF}^{53}$ although this is unproven.

The vast majority of events involving gadoterate meglumine are summarized in a 2015 article reviewing data from clinical study and patient safety databases, as well as postmarketing safety studies. ${ }^{56}$ According to this article, as of September 2015, there have been 44 cases reported with a suspicion of NSF involving GBCAs; of these, administration of gadoterate meglumine was involved in 18 cases (of which 17 were multiagent cases). Upon further review, only 7 of these cases were deemed confirmed or consistent with NSF, and these were all confounded cases. ${ }^{56}$ In our review, we found 1 potentially unconfounded case of NSF following administration of gadoterate meglumine in the literature; it was reported in 2006 in a nondialysis patient with CKD from Denmark who underwent 2 MRI scans and received a total dose larger than $30 \mathrm{~mL} .^{57}$ It is unclear from that article whether the 2 MRI scans both used gadoterate meglumine and we attempted to contact the authors for clarification but were unsuccessful. Other important studies evaluating the safety of gadoterate meglumine with respect to NSF are summarized in Appendix C. 
Gadoteridol. Gadoteridol (marketed as ProHance; Bracco Pharmaceuticals) is a macrocyclic, nonionic agent, which was first approved by the FDA in 1992 and later by Health Canada in 1996. Currently, it is the only agent approved by the FDA for a cumulative dose of $0.3 \mathrm{mmol} / \mathrm{kg}$ and is classified as a group II agent by the ACR ${ }^{38}$ Gadoteridol is primarily eliminated by the kidneys, with over $94 \%$ excreted within 24 hours after injection. ${ }^{58}$ Gadoteridol has one of the highest thermodynamic stability constants among the approved GBCAs at $23.8^{39}$ and is one of the most kinetically inert. ${ }^{59}$

As of 2014, a literature review of regulatory databases identified 22 of 382 histologically proven cases of NSF with either gadobenate dimeglumine or gadoteridol; however, all 22 cases involving these agents were confounded. ${ }^{60}$ The review did not indicate which other GBCAs these patients were initially exposed to, or the number of times they were exposed to a particular agent. A different study cites that multiagent NSF cases involving gadoteridol were confounded by prior administration of either gadodiamide or gadopentetate dimglumine ${ }^{61}$; however, it is unclear whether the patients from the latter study were included in the 2014 literature review. A letter dated June 2017 from Bracco Pharmaceuticals confirms that they are aware of a total of 37 confounded cases involving gadoteridol, mostly involving gadodiamide and/or gadopentetate dimeglumine. ${ }^{43}$

A review from 2017 identified only 2 unconfounded cases of NSF with gadoteridol; however, we could not find the source for this to confirm. ${ }^{39}$ Potentially, one of the cases was described in another study from MedWatch data, which reported that the patient had received 5 injections of gadoteridol in a 2-year period before the development of NSF. ${ }^{62} \mathrm{~A}$ literature search by Bracco Pharmaceuticals acknowledges this as an unconfounded case of NSF but with 6 high doses of gadoteridol; however, they indicate that no other instances of single-agent NSF associated with gadoteridol administration have been reported. ${ }^{43}$

There have been both retrospective and prospective, multicenter studies focused on gadoteridol use in relation to CKD and NSF development. Even with some patients receiving higher doses for magnetic resonance angiography studies, there have been no reports of NSF developing within 2 years of observation post-injection for patients with category G3-5 CKD. ${ }^{25,63}$

Gadobutrol. Gadobutrol, marketed by Bayer Healthcare Pharmaceuticals (Berlin, Germany) as Gadovist (a macrocyclic, nonionic GBCA) was approved by Health Canada in 1999 and by the FDA in 2011. It is classified as a group II by the $\mathrm{ACR}^{38}$ and has a thermodynamic stability constant of 21.8. Several clinical trials and postmarketing surveillance studies have indicated that gadobutrol is well-tolerated among diverse patient populations. ${ }^{64-67}$ After injection, gadobutrol is rapidly distributed into the extracellular space; elimination is primarily by the kidneys, with $100 \%$ excreted within 72 hours in healthy adults. ${ }^{68}$ Likewise, for patients with mild or moderate CKD (eGFR between 30 and $80 \mathrm{~mL} /$ $\min / 1.73 \mathrm{~m}^{2}$ ), a standard dose of gadobutrol was renally cleared within 72 hours; however, in patients with severely impaired renal function $\left(\leq 30 \mathrm{~mL} / \mathrm{min} / 1.73 \mathrm{~m}^{2}\right.$ but not requiring dialysis), recovery in the urine was approximately $80 \%$ even after 120 hours. ${ }^{69}$ However, all gadolinium could be recovered in patients with severe renal insufficiency over a 6 -day period with dialysis, ${ }^{70}$ suggesting minimal, if any, gadolinium dissociation over this time frame.

As of December 2015, more than 5.7 million injections have been given to patients, with 12 reports of patients experiencing NSF-like symptoms after injection. ${ }^{71}$ Of these, only 3 cases were found to be unconfounded. One patient when first exposed to gadobutrol apparently had category G3 CKD (limitations pertaining to the reported stage of renal disease in this patient are discussed in the guideline section of the article); another had insulin-dependent diabetes and was on hemodialysis when exposed to gadobutrol, ${ }^{72}$ and the third patient had end-stage renal failure when exposed to gadobutrol for the first time, ${ }^{73}$ although it is unclear whether this was a true case of NSF. ${ }^{74}$ For multiagent cases of NSF, the patient was previously exposed to gadopentetate dimeglumine within 6 months prior to gadobutrol. ${ }^{75}$ No details could be found regarding the other 8 cases.

Recently, the results of the prospective, multicenter "GRIP" (Gadobutrol in Renally Impaired Patients) study were released $^{67}$; 927 patients with category G3-5 CKD were enrolled (category G3 586/927 and category G4 or G5 284/927), given $0.1 \mathrm{mmol} / \mathrm{kg}$ gadobutrol and followed for 2 years post-injection for signs of NSF. Similar to other studies, no incidences of NSF were reported.

\section{Screening for Compromised Renal Function to Identify At-Risk Patients for NSF}

The documented increased risk for development of NSF following GBCA administration in patients with AKI, with severe CKD, and on dialysis ${ }^{24,76,77}$ makes screening for renal disease important prior to GBCA administration. Traditionally, screening for renal dysfunction prior to GBCA administration was considered of paramount importance to reduce the incidence of NSF by identifying at-risk patients. The eGFR, which can be calculated from serum creatinine concentration, age, ethnicity, and gender, is a better measure of renal function compared with serum creatinine alone. ${ }^{78}$ Routine screening for CKD in asymptomatic adults before enhanced MRI is now considered controversial. ${ }^{79-82}$ Obtaining blood samples to determine eGFR on all patients referred for GBCA-enhanced MRI leads to considerable expense for an anticipated minimal benefit, particularly considering the exceedingly low risk of developing NSF with macrocyclic and newer linear GBCA, and furthermore may not identify patients with AKI. ${ }^{83,84}$ Another approach would 
Table 2. Screening Questionnaire to Be Administered to the Outpatient Population to Identify Renal Disease at Time of MRI Scheduling (for Institutions Using Macrocyclic Agents and Newer Linear GBCA) and Also Immediately Before MRI for Institutions Which Use Gadodiamide, Gadopentetate Dimeglumine, and Gadoversetamide.

\begin{tabular}{lll}
\hline $\begin{array}{l}\text { Have you ever been told you have } \\
\text { renal problems? }\end{array}$ & Yes & No \\
$\begin{array}{l}\text { Have you ever been told you have } \\
\text { protein in your urine? }\end{array}$ & Yes & No \\
$\begin{array}{l}\text { Do you have high blood pressure? } \\
\text { Do you have diabetes? }\end{array}$ & Yes & No \\
$\begin{array}{l}\text { Do you have gout? } \\
\text { Have you ever had kidney surgery? }\end{array}$ & Yes & No \\
Are you on dialysis? & Yes & No \\
\hline
\end{tabular}

Note. Pregadolinium screening questionnaire for identifying patients at risk of poor renal function, adapted from Choyke et al. ${ }^{88} \mathrm{MRI}=$ magnetic resonance imaging; GBCA = gadolinium-based contrast agents.

${ }^{a}$ Not included in the original Choyke survey but important to clarify prior to administration of GBCA. The panel suggests the question be asked to the patient at time of MRI scheduling and at time of MRI.

be to ask patients whether they have kidney disease or use a combination of blood work and surveys ${ }^{85}$; however, patient awareness of their renal function is poor, and directly asking patients whether they have CKD is likely not an effective approach to screening. . $^{86,87}$

A questionnaire developed by Choyke et $\mathrm{al}^{88}$ has been shown to effectively stratify patients by risk of $\mathrm{NSF}^{89}$ and includes 6 questions (Table 2). Using these 6 questions at time of MRI scheduling and scanning to predict eGFR $<30$ $\mathrm{mL} / \mathrm{min} / 1.73 \mathrm{~m}^{2}$ in 665 patients, Sena et al found that answering "no" to all questions both times the questionnaire was administered had a sensitivity of $100 \%$ (95\% confidence interval $59 \%-100 \%){ }^{89}$ In this same study, only 2 patients with eGFR $<30 \mathrm{~mL} / \mathrm{min} / 1.73 \mathrm{~m}^{2}$ would have been missed if the questionnaire was only administered at time of MRI scheduling. In 2015, Too et al also found the Choyke questionnaire to have $100 \%$ sensitivity for detection of eGFR less than $30 \mathrm{~mL} / \mathrm{min} / 1.73 \mathrm{~m}^{2}$ in a study of 1361 outpatients when serum creatinine was measured at time of scanning. ${ }^{90}$ The Choyke questionnaire was not found to be very specific, with specificities ranging from $44 \%$ and $74 \%$ in these 2 studies ${ }^{89,90}$; however, the extremely high sensitivity is the desired outcome when applying the questionnaire to identify patients with possible renal dysfunction. Choyke et al did not find age to be a significant predictor of renal function. ${ }^{88}$ In addition to the questions included in the Choyke questionnaire, dialysisdependent patients must clearly also be identified before MRI.

Given the exceedingly low risk of NSF when using standard doses of macrocyclic and newer linear GBCA, the panel unanimously favored that in outpatients, screening for renal disease with the questionnaire at the time of MRI scheduling only when using these agents was sufficient and that it was not necessary to repeat the questionnaire on the day of the test $^{13,63,67,91,92}$; however, the patient should be asked again at time of MRI scanning whether they are presently receiving dialysis. At institutions that continue to use high-risk agents (gadodiamide, gadopentetate dimeglumine, and gadoversetamide) ${ }^{42}$ the panel suggests using the pregadolinium screening questionnaire both at time of MRI scheduling and immediately prior to MRI scanning to maximize sensitivity for detection of renal impairment. ${ }^{88-90}$ Institutions which use high-risk agents should also consider switching to a macrocyclic or newer linear agent for patients approaching category G4 CKD, and in patients with category G4 or G5 CKD or on dialysis, high-risk agents are absolutely contraindicated. For outpatients answering "yes" to the questionnaire, a serum creatinine is required for estimation of eGFR. The panel suggests obtaining a serum creatinine, if not available or older than 3 to 6 months from the date of administration of the screening questionnaire. For inpatients, the panel endorses what has been recommended by the ACR, namely obtaining an eGFR within 48 hours of anticipated GBCAenhanced MRI. ${ }^{42}$ Inpatients should also be assessed for potential AKI regardless of their eGFR, because eGFR is not always representative of renal function in this setting. Several helpful clinical tools include the Acute Kidney Injury Network (AKIN) and Kidney Disease Improving Global Outcomes (KDIGO) criteria. ${ }^{93-95}$

We acknowledge the current position of the ACR which suggests optional screening of renal function when using "class II" agents (macrocyclic GBCA and gadobenate dimeglumine) due to the "few if any" unconfounded cases of NSF attributed to these agents and that dialysis would not be administered to a patient not already on dialysis when receiving a class II GBCA even with AKI or severe CKD. ${ }^{42}$ The panel in general agreed with this strategy; however, at this time unanimously suggested an intermediate approach using less rigid screening parameters than what has been suggested previously by the CAR. For institutions using macrocyclic agents and newer linear GBCA, we do not consider screening with the questionnaire at time of MRI scheduling to be particularly onerous and plan to revisit the need for routine outpatient screening when reevaluating the guideline at our next audit.

In conclusion, this document reviews the relevant literature regarding NSF in an era of increased physician and patient awareness of disease and associated risk factors (eg, renal impairment, increased and repeated dosing of GBCA, and dialysis) and specifically reevaluates the role of GBCAenhanced MRI using newer macrocyclic and linear agents. Guidelines were developed by a panel of radiologists representing the CAR and nephrologist members of the CSN based on the best available evidence and may provide a framework for use of GBCA in renal impairment in clinical practices in Canada. In summary, the risk of developing NSF in patients with $\mathrm{AKI}$, with severe $\mathrm{CKD}$, and on dialysis when macrocyclic or newer linear GBCAs are used is exceedingly low when standard dosages are prescribed and short-term repeat injections are avoided. We recommend screening for 
renal impairment with the 6-question Choyke questionnaire at time of MRI scheduling in facilities using macrocyclic and newer linear agents and also advise that the questionnaire should be repeated at time of MRI for facilities using gadodiamide, gadopentetate dimeglumine, and gadoversetamide. In patients with AKI or severe CKD, alternate diagnostic tests should be considered first; however, if GBCA-enhanced MRI is considered medically necessary, it can be performed using macrocyclic or newer linear agents; gadodiamide, gadopentetate dimeglumine, and gadoversetamide remain absolutely contraindicated. Patient informed consent is recommended and can be obtained by a physician or their delegate. Dialysis should only be performed in patients who are already dialysis dependent, and there is no reliable evidence to suggest that initiating dialysis, switching from peritoneal to hemodialysis, or altering dialysis regimens reduces the risk of developing NSF.

\section{Appendix A}

\section{CAR Clinical Practice Guidelines for Administration of GBCA in Renal Impairment}

1. Use of gadolinium-based contrast agents (GBCA) in patients with mild renal impairment with eGFR between 60 and $90 \mathrm{~mL} / \mathrm{min} / 1.73 \mathrm{~m}^{2}$

- There is no evidence to suggest patients with mild renal impairment (category G2 CKD) are at increased risk of NSF, and no special precautions should be taken in these patients.

2. Use of GBCA in patients with moderate renal impairment (eGFR between 30 and $60 \mathrm{~mL} / \mathrm{min} / 1.73 \mathrm{~m}^{2}$ )

- For patients with moderately reduced kidney function, GBCA can be administered safely without any substantial risk of developing NSF or need for informed consent. The risk of developing NSF in moderate CKD is exceedingly rare.

- Qualifying statements:

- Studies reporting cases of NSF in patients receiving GBCA with eGFR above 30 $\mathrm{mL} / \mathrm{min} / 1.73 \mathrm{~m}^{2}$ generally occurred in patients with $\mathrm{AKI}{ }^{24,25}$

- One study reported 3 cases of NSF in patients with eGFR above $30 \mathrm{~mL} / \mathrm{min} / 1.73$ $\mathrm{m}^{2}$; however, these patients were grouped with patients that also had category G4 CKD, the authors did not specify whether the patients had AKI or provide the patients eGFR levels. Moreover, the authors did not indicate when the eGFR was calculated, which becomes problematic for this particular study because the range of time between measurement of Creatinine and MRI was up to 83 days. ${ }^{57}$
The authors did not reply to a request for this additional information.

- In one case report, a single patient with eGFR above $30 \mathrm{~mL} / \mathrm{min} / 1.73 \mathrm{~m}^{2}$ reportedly developed NSF. The eGFR in this case report varied; however, ranged between 34.4 and $31.8 \mathrm{~mL} / \mathrm{min} / 1.73 \mathrm{~m}^{2}$ during the course of the patients follow-up which consisted of 7 MRI examinations. ${ }^{96}$

- Given the paucity of reported cases of NSF in patients with moderate CKD, the panel suggested that no special precautions are required in this patient population. Institutions which use gadodiamide, gadopentetate dimeglumine, and gadoversetamide may optionally consider a macrocyclic or newer linear GBCA when renal function approaches $30 \mathrm{~mL} /$ $\min / 1.73 \mathrm{~m}^{2}$.

- Regular vendor suggested dosing is recommended, half or quarter dosing is not considered necessary, and double or triple dosing is not recommended.

3. Use of GBCA in patients with category G4 or G5 CKD (eGFR less than $30 \mathrm{~mL} / \mathrm{min} / 1.73 \mathrm{~m}^{2}$ ) or dialysis dependent patients.

- For patients with severely reduced kidney function and those on dialysis, examinations should be considered on a case by case basis. Alternative diagnostic tests (eg, unenhanced MRI, CT, ultrasound, biopsy, scintigraphic examinations, etc) should be considered before GBCA are prescribed. When another diagnostic modality is not available or considered inferior to enhanced MRI, and MRI is deemed necessary for patient care, then gadoliniumenhanced examinations using macrocyclic or newer linear GBCA may be performed with patient informed consent citing an exceedingly low risk (much less than 1\%) of NSF based on available literature. Qualifying statements:

- Gadodiamide, gadopentetate dimeglumine, and gado-versetamide are absolutely contraindicated. ${ }^{9-11}$ The risk of NSF when one of these agents is used in AKI or severe renal impairment is estimated to be between $1 \%$ and $7 \%{ }^{38}$; the panel could not envision a scenario where an imaging facility in Canada which is required to perform enhanced MRI in AKI or category G4 or G5 CKD could not obtain a macrocyclic or a newer linear ionic agent. This would apply to institutions requiring an agent on a special-needs basis and the panel felt that institutions should be exempt from single vendor contrast contracts in these instances. 
- Double or triple dosing of GBCA should not be performed. There is a documented increase in the incidence of NSF with increased amount of GBCA administration (either at the same administration session or cumulatively) ${ }^{76,97}$; however, there are cases of NSF reported when patients have received standard dosing. ${ }^{33}$ The panel felt there is insufficient evidence to support the notion that reducing the dose of GBCA beyond standard dosing further minimizes the risk of NSF, and studies evaluating the minimum required dose of GBCA to maintain diagnostic accuracy of MRI are lacking.

- When possible, repeat contrast-enhanced MRI examinations should be delayed until sufficient time has passed to allow for excretion. Clearance of GBCA is partly agent specific and the panel suggests institutions review the clearance of their agents to establish a safe interval between repeated injections.

- Informed consent can be obtained by a radiologist or a suitable delegate (including MRI technologists) and discussions with the patient should include references to the exceedingly low number of reported cases of NSF in patients with category G4 or G5 CKD using macrocyclic and newer linear agents. The panel makes no specific recommendation on use of verbal or written consent which can be an institutional decision. A sample of pertinent information to be discussed with the patient may be viewed on the CAR website: www.car.ca

- Patients should be monitored for signs and symptoms of NSF when they have received a GBCA with eGFR $<30 \mathrm{~mL} / \mathrm{min} / 1.73 \mathrm{~m}^{2}$ or are on dialysis and any potential cases reported (after histopathological confirmation of diagnosis with skin punch biopsy). We suggest monitoring be performed by the patients' regular (typically a general practitioner) physician. Monitoring can be performed based on patient symptomatology and with routine annual physical examinations. We suggest that monitoring occur for a 2-year period following the administration of GBCA; however, a case of NSF occurring up to 9 years after administration of GBCA has been reported. ${ }^{98}$ The reporting of cases of potential NSF should be documented and filed with a regulatory body; we suggest Health Canada's Adverse Reaction Database.

- There is insufficient evidence to support the use of macrocyclic ionic GBCA (eg, gadoterate meglumine) compared with macrocyclic nonionic GBCA or macrocyclic GBCA vs newer linear (gadobenate dimeglumine and gadoxetate disodium) GBCA to reduce the risk of NSF when GBCA are administered in category G4 or G5 renal dysfunction. Studies evaluating the risk of NSF when selecting a GBCA in order of decreasing meta-stability are needed; however, unlikely to be sufficiently powered because the incidence of disease in patients who have received all of these agents with compromised renal function is very low. Data regarding cases of NSF with gadoxetate disodium is limited to the relatively lower number of injections compared with extracellular agents.

4. Dialysis

- In patients who are already receiving dialysis (peritoneal dialysis [PD] or hemodialysis [HD]), dialysis should continue after receiving GBCA. HD should be performed the same day as GBCA administration, ideally within 2 to 3 hours of MRI. There is insufficient evidence to support initiation of dialysis, change from PD to HD, or altering dialysis prescription to reduce the risk of NSF.

- Qualifying statements:

- HD efficiently removes GBCA with about $70 \%$ clearance in 1 session and $>95 \%$ clearance after 3 sessions. Therefore, in patients who have received a GBCA and underwent HD, the half-life of GBCAs in circulation approaches that in an individual with normal kidney function. ${ }^{99,100}$

- Little evidence exists on rates of NSF with differing duration between GBCA and subsequent dialysis. To minimize time of circulating GBCA and subsequent transmetallation and deposition, earlier HD might be potentially beneficial. Hence, for patients already on HD, HD should be scheduled soon after exposure, ideally within 2 to 3 hours after GBCA-enhanced MRI. ${ }^{101-104}$

- Multiple frequent dialysis sessions have been previously advocated to promote Gadolinium clearance $^{53,105}$; however, there are no formal studies showing that these practices reduce the incidence of NSF. ${ }^{100}$ The panel felt that there is insufficient evidence to support altering HD prescription to further reduce the risk of NSF after administration of either a macrocyclic or a newer linear GBCA.

- $\mathrm{PD}$ is less efficient than HD at gadolinium clearance. $^{101,106}$ The literature regarding the use of PD to reduce the risk of NSF when a GBCA is administered is scarce and restricted 
primarily to case reports. Increasing the number of exchanges can increase GBCA clearance, but little empiric data exist on its effect on reducing the risk of NSF. ${ }^{107}$ Patients on PD also have residual kidney function, which can provide additional GBCA clearance. Thus, though increasing the number of exchanges (eg, a temporary switch to automated or cycler PD) could hasten GBCA clearance, decisions regarding altering PD should be considered on a per-patient and institutional basis considering logistical aspects and residual kidney function.

- While HD does clear gadolinium more efficiently than PD, cases of NSF have occurred despite patients receiving HD promptly following GBCA. ${ }^{103,108-110}$ Temporary HD requires a central line placement with attendant cost, inconvenience, and potential complications. Thus, though it has been suggested that temporary HD could be considered after GBCA administration in patients on $\mathrm{PD},{ }^{101}$ the panel felt there is insufficient evidence to support switching patients on PD to HD to reduce the risk of NSF.

- Routine nephrology consultation is not warranted for patients on dialysis or with eGFR < $30 \mathrm{~mL} / \mathrm{min} / 1.73 \mathrm{~m}^{2}$ who are deemed to require GBCA; however, in patients who are dialysis dependent the dialysis service should be contacted to coordinate anticipated changes in HD scheduling and for patients on PD to consider potential alterations in PD prescription.

\section{Acute kidney injury}

- Patients with AKI should be managed similar to those with eGFR $<30 \mathrm{~mL} / \mathrm{min} / 1.73 \mathrm{~m}^{2}$ (see guideline statement 2) with the caveat that if GBCA administration can be delayed it should be until renal function stabilizes or ameliorates depending on the patients underlying cause for acute renal dysfunction.

- Qualifying statements:

- NSF has been reported in patients with AKI with a baseline eGFR $>30 \mathrm{~mL} / \mathrm{min} / 1.73$ $\mathrm{m}^{2}{ }^{24,25}$ Because kidney function is not stable in patients with AKI, risk assessment for NSF should not be made on the basis of eGFR alone.

- Little data exist on GBCA and NSF in critically ill patients with AKI receiving continuous renal replacement therapy (CRRT) or sustained low-efficiency dialysis (SLED); however, both modalities would be anticipated to provide sufficient clearance of GBCA approximating HD over 24 hours.
6. Pediatric patients

- Pediatric patients with severely reduced kidney function (eGFR $<30 \mathrm{~mL} / \mathrm{min} / 1.73 \mathrm{~m}^{2}$ ), AKI, or on dialysis should be managed according to guidelines 3,4 , and 5 .

- The number of reported cases of NSF in the pediatric population is lower than in the adult population. ${ }^{109,111}$ There is no convincing evidence that pediatric patients have an increased risk compared with adults.

- eGFR should be calculated using the bedside Schwartz equation. ${ }^{112,113}$

- eGFR during the neonatal period is lower especially in preterm infants, and serum creatinine is not a reliable marker. ${ }^{114-116}$

7. Screening for compromised renal function to identify at-risk patients for NSF

- Outpatients: At institutions using macrocyclic agents or newer linear ionic agents, a modified version of the Choyke screening questionnaire (Table 2) is suggested to screen for renal disease at time of MRI scheduling only. At institutions using gadodiamide, gadopentetate dimeglumine, and gadoversetamide, screening with the modified Choyke questionnaire is considered mandatory at time of MRI scheduling and the questionnaire should also be repeated at time of MRI to maximize detection of renal dysfunction.

- Inpatients: Inpatients should be assessed for AKI regardless of their eGFR, because eGFR is not always representative of renal function in this setting. Several helpful clinical tools include the Acute Kidney Injury Network (AKIN) and Kidney Disease Improving Global Outcomes (KDIGO) criteria.

- Qualifying statements:

- The questionnaire developed by Choyke et $\mathrm{al}^{88}$ has been shown to effectively stratify patients by risk of $\mathrm{NSF}^{89}$ and that answering "no" to all questions is extremely sensitive to detect patients with eGFR less than $30 \mathrm{~mL} /$ $\min / 1.73 \mathrm{~m}^{2} .{ }^{89,90}$

- For macrocyclic and newer linear GBCAs when the screening questionnaire (and subsequent serum creatinine levels where appropriate) is obtained remote from the date of MRI, the screening process may need to be repeated to exclude the possibility of interval development of renal disease in patients screened too far in advance of GBCA administration. A specific time period between screening and MRI was not proposed by the panel; however, when a greater than 3-to-6 month time interval between screening and MRI has elapsed between time of screening and MRI, then 
repeat screening is probably warranted. Institutions using gadodiamide, gadopentetate dimeglumine, and gadoversetamide should apply stricter time frames.

- The ACR manual on contrast media version 10.3 suggests optional screening for renal dysfunction with questionnaire or laboratory testing when a macrocyclic agent or gadobenate dimeglumine is being used. ${ }^{38}$ The panel agreed that routine screening of patients for renal dysfunction when macrocyclic or newer linear GBCAs are used may potentially be unnecessary; however, it currently suggests a less rigorous screening methodology (rather than no screening at all) than what was formerly recommended by the CAR by using a modified version of the Choyke questionnaire (Table 2). Our current recommendation is in agreement with the European Society of Urogenital Radiology (ESUR) guidelines ${ }^{117}$ and we intend to revisit this controversial topic in 2 years with plans to harmonize CAR and ACR guidelines for screening pending a review of the published literature in the interim.

\section{Appendix B}

Several studies have reported a $0 \%$ incidence of NSF after administration of gadobenate dimeglumine, some using restrictive measures on patients with renal dysfunction. ${ }^{13,23,118-120}$ In a large, 1999-2009 retrospective 2-center study in the United Kingdom, in patients undergoing GBCA-enhanced MRI, Chrysochou et al reported no NSF events in 74 patients with category G5 CKD without dialysis who received gadobenate dimeglumine at the standard dose $(0.1 \mathrm{mmol} / \mathrm{kg}){ }^{23} \mathrm{In}$ the same study, Chrysochou et al reported no NSF events in 272 patients with category G4 CKD without dialysis who received gadobenate dimeglumine at full dose. ${ }^{23}$ Similarly, in a large 2000-2008 retrospective study collecting data from 2 American academic centers, Altun et al reported no NSF events in over 25,000 patients, including 549 dialysis or atrisk patients (eg, category G4 or G5 renal disease), who received gadobenate dimeglumine at half dose. ${ }^{118}$ In a 20072008 retrospective single-center study, Martin et al reported no NSF events in 784 patients on dialysis who received gadobenate dimeglumine at a mean dose of $0.11 \mathrm{mmol} / \mathrm{kg}$ $(0.05-0.75 \mathrm{mmol} / \mathrm{kg}) .{ }^{119}$ In a $2002-2010$ retrospective singlecenter study, in patients undergoing contrast-enhanced MRI according to the 2007 restrictive GBCA guidelines of the Massachusetts General Hospital, Wang et al reported no NSF events in 36 patients with category G4 or G5 CKD, including 4 with dialysis at the moment of the MRI procedure. ${ }^{13}$ The same study found no cases of NSF in 6454 patients with category G3 CKD who received gadobenate dimeglumine and/ or gadopentetate dimeglumine (Magnevist). ${ }^{13}$ In a $2007-$ 2013 retrospective single-center study, in patients sustaining gadolinium-enhanced MRI examinations before liver transplantation, Shaffer et al reported no NSF events in 64 CKD patients $\left(\mathrm{eGFR}<60 \mathrm{~mL} / \mathrm{min} / 1.73 \mathrm{~m}^{2}\right.$ ) who received gadobenate dimeglumine at half-dose $(0.05 \mathrm{mmol} / \mathrm{kg}) .{ }^{120}$ A 2010 single-center study by Nandwana et al retrospectively evaluated 401 renally impaired patients, including 246 on hemodialysis and 57 on peritoneal dialysis, and in which $93 \%$ of patients had category G4 or G5 CKD. Patients received an off-label, increased dose of $0.15 \mathrm{mmol} / \mathrm{kg}$ of gadobenate dimeglumine; however, no cases of NSF were detected. ${ }^{121}$

In a 2008-2013 prospective multicenter cohort study sponsored by Bracco Pharmaceuticals, Soulez et al reported no NSF events in 45 patients with category G4 or G5 CKD, including 20 on hemodialysis and 6 on peritoneal dialysis, who received gadobenate dimeglumine at a mean dose of $0.11 \pm 0.04 \mathrm{mmol} / \mathrm{kg} .{ }^{63}$ Finally, a $2008-2014$ retrospective single-center study found no cases of NSF in 3819 patients with severe CKD who received gadobenate dimeglumine. ${ }^{91}$ Patients were administered a mean dose of $23 \mathrm{~mL}$ (range, 3-45 mL), which corresponded to $0.05 \mathrm{mmol} / \mathrm{kg}$ for MRI and $0.1 \mathrm{mmol} / \mathrm{kg}$ for Magnetic Resonance Angiography (MRA). ${ }^{91}$

\section{Appendix C}

Several studies have evaluated the safety of gadoterate meglumine in patients with acute or chronic kidney disease. ${ }^{23,122-125}$ In the FINEST study, a 2005-2006 retrospective multicenter study from France, with a cohort of 232 patients undergoing contrast-enhanced MRI, a majority of whom (176/232) received gadoterate meglumine, Janus et al reported no patients with NSF events in 96 patients with CKD category G5 who received gadoterate meglumine. ${ }^{122}$ The same study reported no patients with NSF events among 39 patients with category G4 CKD who received gadoterate meglumine. ${ }^{122}$ In a large, 1999-2009 retrospective bicenter study in the United Kingdom, in patients undergoing GBCA-enhanced MRI, Chrysochou et al reported no NSF events in 23 patients with category G4 CKD without dialysis who received gadoterate meglumine at the standard dose $(0.1 \mathrm{mmol} / \mathrm{kg}){ }^{23}$

In the RESCUE trial, a 2008-2011 prospective European multicenter study, Deray et al reported no NSF events at 3-month follow-up in 70 patients with category G3 or G4 CKD who received gadoterate meglumine at full dose $(0.1$ $\mathrm{mmol} / \mathrm{kg}){ }^{123}$ Furthermore, in the 2009-2011 Pro-FINEST prospective multicenter trial, Amet et al reported no patients with NSF events in 255 end-stage renal disease (category G5 CKD) patients undergoing long-term dialysis who received gadoterate meglumine at variable doses. ${ }^{124}$ Most recently, in the results from the 2008-2013 SECURE study - an international, multicenter, prospective observational study evaluating the safety profile of gadoterate meglumine-Soyer et al found no cases of NSF among 476 post-MRI patients with category G3-5 CKD who received gadoterate meglumine at 
full dose; however the follow-up duration was less than 3 months in 160 of 476 patients. ${ }^{125}$

\section{Ethics Approval and Consent to Participate}

Not applicable.

\section{Consent for Publication}

All authors consented for publication

\section{Availability of Data and Materials}

Publicly available

\section{Declaration of Conflicting Interests}

The author(s) declared no potential conflicts of interest with respect to the research, authorship, and/or publication of this article.

\section{Funding}

The author(s) received no financial support for the research, authorship, and/or publication of this article.

\section{ORCID iD}

Casey Hurrell (iD https://orcid.org/0000-0003-0453-2576

\section{References}

1. Granata V, Cascella M, Fusco R, et al. Immediate adverse reactions to gadolinium-based MR contrast media: a retrospective analysis on 10,608 examinations. Biomed Res Int. 2016;2016:3918292.

2. Neuberger J, Madden S, Collett D. Review of methods for measuring and comparing center performance after organ transplantation. Liver Transpl. 2010;16(10):1119-1128.

3. Niendorf HP, Dinger JC, Haustein J, Cornelius I, Alhassan A, Clauss W. Tolerance data of Gd-DTPA: a review. Eur $J$ Radiol. 1991;13(1):15-20.

4. Abujudeh HH, Kosaraju VK, Kaewlai R. Acute adverse reactions to gadopentetate dimeglumine and gadobenate dimeglumine: experience with 32,659 injections. AJR Am J Roentgenol. 2010;194(2):430-434.

5. Jung JW, Kang HR, Kim MH, et al. Immediate hypersensitivity reaction to gadolinium-based MR contrast media. Radiology. 2012;264(2):414-422.

6. Prince MR, Zhang H, Zou Z, Staron RB, Brill PW. Incidence of immediate gadolinium contrast media reactions. AJR Am J Roentgenol. 2011;196(2):W138-W143.

7. Runge VM. Safety of approved MR contrast media for intravenous injection. J Magn Reson Imaging. 2000;12(2):205-213.

8. Boyd AS, Zic JA, Abraham JL. Gadolinium deposition in nephrogenic fibrosing dermopathy. J Am Acad Dermatol. 2007;56(1):27-30.

9. Government of Canada. Gadolinium-Containing Contrast Agents-Update on Nephrogenic Systemic Fibrosis/NephrogenicFibrosingDermopathy (NSF/NFD)-NoticetoHospitals. http:/healthycanadians.gc.ca/recall-alert-rappel-avis/hcsc/2013/36711a-eng.php. Published 2013. Accessed August $1,2017$.

10. U.S. Department of Health and Human Services. FDA Drug Safety Communication: New Warnings for Using Gadolinium-
Based Contrast Agents in Patients With Kidney Dysfunction. https://www.fda.gov/Drugs/DrugSafety/ucm223966.htm. Published 2010. Accessed August 1, 2017.

11. European Medicines Agency. Gadolinium-Containing Contrast Agents. http://www.ema.europa.eu/ema/index.jsp?curl=pages/ medicines/human/referrals/Gadolinium-containing_contrast_ agents/human_referral_000182.jsp. Published 2010. Accessed August 1, $201 \overline{7}$.

12. Khawaja AZ, Cassidy DB, Al Shakarchi J, McGrogan DG, Inston NG, Jones RG. Revisiting the risks of MRI with Gadolinium based contrast agents-review of literature and guidelines. Insights Imaging. 2015;6(5):553-558.

13. Wang Y, Alkasab TK, Narin O, et al. Incidence of nephrogenic systemic fibrosis after adoption of restrictive gadolinium-based contrast agent guidelines. Radiology. 2011;260(1): 105-111.

14. Altun E, Martin DR, Wertman R, Lugo-Somolinos A, Fuller ER III, Semelka RC. Nephrogenic systemic fibrosis: change in incidence following a switch in gadolinium agents and adoption of a gadolinium policy - report from two U.S. universities. Radiology. 2009;253(3):689-696.

15. Canada H. Canada Vigilance Adverse Reaction Online Database. http://webprod3.hc-sc.gc.ca/arquery-rechercheei/ report-rapport.do?lang=eng\&id=000391259. Published 2017. Accessed August 10, 2017.

16. Behzadi AH, Zhao Y, Farooq Z, Prince MR. Immediate allergic reactions to gadolinium-based contrast agents: a systematic review and meta-analysis. Radiology. 2018:286:471482.

17. Hao D, Ai T, Goerner F, Hu X, Runge VM, Tweedle M. MRI contrast agents: basic chemistry and safety. J Magn Reson Imaging. 2012;36(5):1060-1071.

18. Forghani R. Adverse effects of gadolinium-based contrast agents: changes in practice patterns. Top Magn Reson Imaging. 2016;25(4):163-169.

19. Thomsen HS, Morcos SK, Almen T, et al. Nephrogenic systemic fibrosis and gadolinium-based contrast media: updated ESUR Contrast Medium Safety Committee guidelines. Eur Radiol. 2013;23(2):307-318.

20. Thomsen HS. Nephrogenic systemic fibrosis: a serious late adverse reaction to gadodiamide. Eur Radiol. 2006;16(12):2619-2621.

21. Mendoza FA, Artlett CM, Sandorfi N, Latinis K, PieraVelazquez S, Jimenez SA. Description of 12 cases of nephrogenic fibrosing dermopathy and review of the literature. Semin Arthritis Rheum. 2006;35(4):238-249.

22. Group KDIGOKCW. KDIGO 2012 clinical practice guideline for the evaluation and management of chronic kidney disease. Kidney Inter Suppl. 2013;3(1):1-150.

23. Chrysochou C, Power A, Shurrab AE, et al. Low risk for nephrogenic systemic fibrosis in nondialysis patients who have chronic kidney disease and are investigated with gadolinium-enhanced magnetic resonance imaging. Clin J Am Soc Nephrol. 2010;5(3):484-489.

24. Sadowski EA, Bennett LK, Chan MR, et al. Nephrogenic systemic fibrosis: risk factors and incidence estimation. Radiology. 2007;243(1):148-157.

25. Prince MR, Zhang H, Morris M, et al. Incidence of nephrogenic systemic fibrosis at two large medical centers. Radiology. 2008;248(3):807-816. 
26. Mazhar SM, Shiehmorteza M, Kohl CA, Middleton MS, Sirlin CB. Nephrogenic systemic fibrosis in liver disease: a systematic review. J Magn Reson Imaging. 2009;30(6):13131322.

27. Chow DS, Bahrami S, Raman SS, et al. Risk of nephrogenic systemic fibrosis in liver transplantation patients. AJR Am J Roentgenol. 2011;197(3):658-662.

28. Smorodinsky E, Ansdell DS, Foster ZW, et al. Risk of nephrogenic systemic fibrosis is low in patients with chronic liver disease exposed to gadolinium-based contrast agents. J Magn Reson Imaging. 2015;41(5):1259-1267.

29. Webb JA, Thomsen HS, Morcos SK, Members of Contrast Media Safety Committee of European Society of Urogenital Radiology. The use of iodinated and gadolinium contrast media during pregnancy and lactation. Eur Radiol. 2005;15(6):1234-1240.

30. Wang PI, Chong ST, Kielar AZ, et al. Imaging of pregnant and lactating patients: part 1, evidence-based review and recommendations. AJR Am J Roentgenol. 2012;198(4):778-784.

31. Thomsen HS, Marckmann P. Extracellular Gd-CA: differences in prevalence of NSF. Eur J Radiol. 2008;66(2):180183.

32. Broome DR. Nephrogenic systemic fibrosis associated with gadolinium based contrast agents: a summary of the medical literature reporting. Eur J Radiol. 2008;66(2):230-234.

33. Wertman R, Altun E, Martin DR, et al. Risk of nephrogenic systemic fibrosis: evaluation of gadolinium chelate contrast agents at four American universities. Radiology. 2008;248(3):799-806

34. Girardi M, Kay J, Elston DM, Leboit PE, Abu-Alfa A, Cowper SE. Nephrogenic systemic fibrosis: clinicopathological definition and workup recommendations. J Am Acad Dermatol. 2011;65(6):1095-1106.e7.

35. Kanda T, Ishii K, Kawaguchi H, Kitajima K, Takenaka D. High signal intensity in the dentate nucleus and globus pallidus on unenhanced T1-weighted MR images: relationship with increasing cumulative dose of a gadolinium-based contrast material. Radiology. 2014;270(3):834-841.

36. McDonald RJ, McDonald JS, Kallmes DF, et al. Intracranial gadolinium deposition after contrast-enhanced MR imaging. Radiology. 2015;275(3):772-782.

37. Stojanov D, Aracki-Trenkic A, Benedeto-Stojanov D. Gadolinium deposition within the dentate nucleus and globus pallidus after repeated administrations of gadolinium-based contrast agents-current status. Neuroradiology. 2016;58:433-441

38. American College of Radiology. ACR Manual on Contrast Media v10.3. Nephrogenic Systemic Fibrosis (NSF). https:// www.acr.org/ /media/ACR/Documents/PDF/QualitySafety/ Resources/Contrast-Manual/Contrast_Media.pdf/\#page $=88$. Published 2017. Accessed August 10, 2017.

39. Fraum TJ, Ludwig DR, Bashir MR, Fowler KJ. Gadoliniumbased contrast agents: a comprehensive risk assessment. $J$ Magn Reson Imaging. 2017;46:338-353.

40. Health Canada. Drug Product Database Online Query. Date unknown. https://health-products.canada.ca/dpd-bdpp/indexeng.jsp. Accessed August 17, 2017.

41. U.S. Food \& Drug Administration. Drug Approval Package: MultiHance (Gadobenate Dimeglumine) Injection \& Injection in Pharmacy Bulk Package. https://www.accessdata.fda.gov/
drugsatfda_docs/nda/2004/021357_021358_Multihance.cfm. Published 2005 . Accessed August 17, 2017.

42. Media ACoDaC. ACR manual on contrast media. J Am Coll Radiol. 2017;10.3.

43. Spinazzi AM. Gadolinium based contrast agents and nephrogenic systemic fibrosis. Formal communication release from Bracco Pharmaceuticals, 2017

44. US Food and Drug Administration. Drug Approval Package: Eovist (Gadoxetate Disodium) Injection. https://www.accessdata.fda.gov/drugsatfda_docs/nda/2008/022090s000TOC. cfm. Published 2008. Accessed August 17, 2017.

45. Zou Z, Ma L. Nephrogenic systemic fibrosis: review of 408 biopsy-confirmed cases. Indian J Dermatol. 2011;56(1):65-73.

46. Lauenstein T, Ramirez-Garrido F, Kim YH, et al. Nephrogenic systemic fibrosis risk after liver magnetic resonance imaging with gadoxetate disodium in patients with moderate to severe renal impairment: results of a prospective, open-label, multicenter study. Invest Radiol. 2015;50(6):416-422.

47. Song KD, Kim SH, Lee J, Kang KA, Kim J, Yoo H. Halfdose gadoxetic acid-enhanced liver magnetic resonance imaging in patients at risk for nephrogenic systemic fibrosis. Eur J Radiol. 2015;84(3):378-383.

48. Oh JW, Oh SN, Choi JI, et al. Does the gadoxetic acidenhanced liver MRI impact on the treatment of patients with colorectal cancer? comparison study with ${ }^{18} \mathrm{~F}$-FDG PET/CT. Biomed Res Int. 2016;2016:8412071.

49. Zech CJ, Korpraphong P, Huppertz A, et al. Randomized multicentre trial of gadoxetic acid-enhanced MRI versus conventional MRI or CT in the staging of colorectal cancer liver metastases. Br J Surg. 2014;101(6):613-621.

50. Park MJ, Hong N, Han K, et al. Use of imaging to predict complete response of colorectal liver metastases after chemotherapy: MR imaging versus CT imaging. Radiology. 2017;284(2):423-431.

51. McInnes MD, Hibbert RM, Inacio JR, Schieda N. Focal nodular hyperplasia and hepatocellular adenoma: accuracy of gadoxetic acid-enhanced MR imaging - a systematic review. Radiology. 2015;277(3):413-423.

52. Elsayes KM, Kielar AZ, Agrons MM, et al. Liver imaging reporting and data system: an expert consensus statement. $J$ Hepatocell Carcinoma. 2017;4:29-39.

53. Bahrainwala JZ, Leonberg-Yoo AK, Rudnick MR. Use of radiocontrast agents in CKD and ESRD. Semin Dial. 2017;30(4):290-304.

54. Lancelot E. Revisiting the pharmacokinetic profiles of gadolinium-based contrast agents: differences in long-term biodistribution and excretion. Invest Radiol. 2016;51(11):691-700.

55. US Food and Drug Administration. Drug Approval Package: Dotarem (Gadoterate meglumine) Injection. https:/www. accessdata.fda.gov/drugsatfda docs/nda/2013/204781 Orig1s000TOC.cfm. Published 2013. Accessed August 17, 2017.

56. de Kerviler E, Maravilla K, Meder JF, et al. Adverse reactions to gadoterate meglumine: review of over 25 years of clinical use and more than 50 million doses. Invest Radiol. 2016;51(9):544-551.

57. Elmholdt TR, Pedersen M, Jorgensen B, et al. Nephrogenic systemic fibrosis is found only among gadolinium-exposed patients with renal insufficiency: a case-control study from Denmark. Br J Dermatol. 2011;165(4):828-836. 
58. McLachlan SJ, Eaton S, De Simone DN. Pharmacokinetic behavior of gadoteridol injection. Invest Radiol. 1992;27(suppl 1):S12-S15.

59. Puttagunta NR, Gibby WA, Smith GT. Human in vivo comparative study of zinc and copper transmetallation after administration of magnetic resonance imaging contrast agents. Invest Radiol. 1996;31(12):739-742.

60. Edwards BJ, Laumann AE, Nardone B, et al. Advancing pharmacovigilance through academic-legal collaboration: the case of gadolinium-based contrast agents and nephrogenic systemic fibrosis-a Research on Adverse Drug Events and Reports (RADAR) report. Br J Radiol. 2014;87(1042):20140307.

61. Lee CU, Wood CM, Hesley GK, et al. Large sample of nephrogenic systemic fibrosis cases from a single institution. Arch Dermatol. 2009;145(10):1095-1102.

62. Reilly RF. Risk for nephrogenic systemic fibrosis with gadoteridol (ProHance) in patients who are on long-term hemodialysis. Clin J Am Soc Nephrol. 2008;3(3):747-751.

63. Soulez G, Bloomgarden DC, Rofsky NM, et al. Prospective cohort study of nephrogenic systemic fibrosis in patients with stage 3-5 chronic kidney disease undergoing MRI with injected gadobenate dimeglumine or gadoteridol. AJR Am J Roentgenol. 2015;205(3):469-478.

64. Prince MR, Lee HG, Lee $\mathrm{CH}$, et al. Safety of gadobutrol in over 23,000 patients: the GARDIAN study, a global multicentre, prospective, non-interventional study. Eur Radiol. 2017;27(1):286-295.

65. Glutig K, Bhargava R, Hahn G, et al. Safety of gadobutrol in more than 1,000 pediatric patients: subanalysis of the GARDIAN study, a global multicenter prospective non-interventional study. Pediatr Radiol. 2016;46(9):1317-1323.

66. Endrikat J, Schwenke C, Prince MR. Gadobutrol for contrastenhanced magnetic resonance imaging in elderly patients: review of the safety profile from clinical trial, post-marketing surveillance, and pharmacovigilance data. Clin Radiol. 2015;70(7):743-751.

67. Michaely HJ, Aschauer M, Deutschmann H, et al. Gadobutrol in renally impaired patients: results of the GRIP study. Invest Radiol. 2017;52(1):55-60.

68. Staks T, Schuhmann-Giampieri G, Frenzel T, Weinmann HJ, Lange L, Platzek J. Pharmacokinetics, dose proportionality, and tolerability of gadobutrol after single intravenous injection in healthy volunteers. Invest Radiol. 1994;29(7):709715.

69. Tombach B, Bremer C, Reimer P, et al. Pharmacokinetics of $1 \mathrm{M}$ gadobutrol in patients with chronic renal failure. Invest Radiol. 2000;35(1):35-40.

70. Tombach B, Bremer C, Reimer P, et al. Using highly concentrated gadobutrol as an MR contrast agent in patients also requiring hemodialysis: safety and dialysability. AJR Am J Roentgenol. 2002;178(1):105-109.

71. Endrikat J, Vogtlaender K, Dohanish S, Balzer T, Breuer J. Safety of gadobutrol: results from 42 clinical phase II to IV studies and postmarketing surveillance after 29 million applications. Invest Radiol. 2016;51(9):537-543.

72. Elmholdt TR, Jorgensen B, Ramsing M, Pedersen M, Olesen AB. Two cases of nephrogenic systemic fibrosis after exposure to the macrocyclic compound gadobutrol. NDT Plus. 2010;3(3):285-287.
73. Wollanka H, Weidenmaier W, Giersig C. NSF after Gadovist exposure: a case report and hypothesis of NSF development. Nephrol Dial Transplant. 2009;24(12):3882-3884.

74. Collidge T, Thomson P, Mark P, Willinek W, Roditi G. Is this really a true case of NSF following Gadovist exposure alone? Nephrol Dial Transplant. 2010;25(4):1352-1353; author reply $1353-1354$.

75. Becker S, Walter S, Witzke O, et al. The German registry for nephrogenic systemic fibrosis: findings from 23 patients. Clin Nephrol. 2010;73(6):426-430.

76. Shabana WM, Cohan RH, Ellis JH, et al. Nephrogenic systemic fibrosis: a report of 29 cases. AJR Am J Roentgenol. 2008;190(3):736-741.

77. Perazella MA, Rodby RA. Gadolinium use in patients with kidney disease: a cause for concern. Semin Dial. 2007;20(3): 179-185.

78. Herts BR, Schneider E, Poggio ED, Obuchowski NA, Baker ME. Identifying outpatients with renal insufficiency before contrast-enhanced CT by using estimated glomerular filtration rates versus serum creatinine levels. Radiology. 2008;248(1):106-113.

79. Kliger AS. Screening for CKD: a pro and con debate. Clin J Am Soc Nephrol. 2014;9(11):1987.

80. Moyer VA, U.S. Preventive Services Task Force. Screening for chronic kidney disease: U.S. Preventive Services Task Force recommendation statement. Ann Intern Med. 2012;157(8):567-570.

81. Saunders MR, Cifu A, Vela M. Screening for chronic kidney disease. JAMA. 2015;314(6):615-616.

82. American Society of Nephrology. ASN Emphasized Need for Early Detection of Kidney Disease, A Silent Killer. Washington, DC: American Society of Nephrology; 2013.

83. Molitoris BA. Measuring glomerular filtration rate in acute kidney injury: yes, but not yet. Crit Care. 2012;16(5):158.

84. Bragadottir G, Redfors B, Ricksten SE. Assessing glomerular filtration rate (GFR) in critically ill patients with acute kidney injury - true GFR versus urinary creatinine clearance and estimating equations. Crit Care. 2013;17(3):R108.

85. Weinreb JC. Impact on hospital policy: Yale experience. $J$ Am Coll Radiol. 2008;5(1):53-56.

86. Coresh J, Byrd-Holt D, Astor BC, et al. Chronic kidney disease awareness, prevalence, and trends among U.S. adults, 1999 to 2000. J Am Soc Nephrol. 2005;16(1):180-188.

87. Plantinga LC, Tuot DS, Powe NR. Awareness of chronic kidney disease among patients and providers. Adv Chronic Kidney Dis. 2010;17(3):225-236.

88. Choyke PL, Cady J, DePollar SL, Austin H. Determination of serum creatinine prior to iodinated contrast media: is it necessary in all patients? Tech Urol. 1998;4(2):65-69.

89. Sena BF, Stern JP, Pandharipande PV, et al. Screening patients to assess renal function before administering gadolinium chelates: assessment of the Choyke questionnaire. AJR Am J Roentgenol. 2010;195(2):424-428.

90. Too CW, Ng WY, Tan CC, Mahmood MI, Tay KH. Screening for impaired renal function in outpatients before iodinated contrast injection: comparing the Choyke questionnaire with a rapid point-of-care-test. Eur J Radiol. 2015;84(7):1227-1231.

91. Martin DR, Kalb B, Mittal A, Salman K, Vedantham S, Mittal PK. No incidence of nephrogenic systemic fibrosis after 
gadobenate dimeglumine administration in patients undergoing dialysis or those with severe chronic kidney disease. Radiology. 2018:286:113-119.

92. Bruce R, Wentland AL, Haemel AK, et al. Incidence of nephrogenic systemic fibrosis using gadobenate dimeglumine in 1423 patients with renal insufficiency compared with gadodiamide. Invest Radiol. 2016;51(11):701-705.

93. Hoste EA, Kellum JA. Acute kidney injury: epidemiology and diagnostic criteria. Curr Opin Crit Care. 2006;12(6):531537.

94. Mehta RL, Kellum JA, Shah SV, et al. Acute Kidney Injury Network: report of an initiative to improve outcomes in acute kidney injury. Crit Care. 2007;11(2):R31.

95. Group KDIGO KAKIW. KDIGO clinical practice guideline for acute kidney injury. Kidney Inter Suppl. 2012;2:1-138.

96. Shikai KKH, Sato N, et al. A case in which renal systemic fibrosis has developed by contrast MRI with repeating renal function with eGFR $>30 \mathrm{ml} / \mathrm{min} / 1.73 \mathrm{~m} 2$. Jpn $J$ Nephrol. 2009;51:676.

97. Pryor JG, Scott GA. Nephrogenic systemic fibrosis: a clinicopathologic study of 6 cases. J Am Acad Dermatol. 2007;57(5):902-903.

98. Do JG, Kim YB, Lee DG, Hwang JH. A case of delayed onset nephrogenic systemic fibrosis after gadolinium based contrast injection. Ann Rehabil Med. 2012;36(6):880-886.

99. Fine DM, Perazella MA. Nephrogenic systemic fibrosis: what the hospitalist needs to know. J Hosp Med. 2010;5(1):46-50.

100. Rodby RA. Dialytic therapies to prevent NSF following gadolinium exposure in high-risk patients. Semin Dial. 2008;21(2):145-149.

101. Rodby RA. Can gadolinium be given safely to a patient on dialysis? Semin Dial. 2011;24(4):370-371.

102. Abu-Alfa A. The impact of NSF on the care of patients with kidney disease. J Am Coll Radiol. 2008;5(1):45-52.

103. Abu-Alfa AK. Nephrogenic systemic fibrosis and gadolinium-based contrast agents. Adv Chronic Kidney Dis. 2011;18(3):188-198.

104. Martin DR, Semelka RC, Chapman A, et al. Nephrogenic systemic fibrosis versus contrast-induced nephropathy: risks and benefits of contrast-enhanced MR and CT in renally impaired patients. J Magn Reson Imaging. 2009;30(6):1350-1356.

105. Gheuens E, Daelemans R, Mesens S. Dialysability of gadoteric acid in patients with end-stage renal disease undergoing hemodialysis. Invest Radiol. 2014;49(8):505-508.

106. Joffe P, Thomsen HS, Meusel M. Pharmacokinetics of gadodiamide injection in patients with severe renal insufficiency and patients undergoing hemodialysis or continuous ambulatory peritoneal dialysis. Acad Radiol. 1998;5(7):491-502.

107. Murashima M, Drott HR, Carlow D, et al. Removal of gadolinium by peritoneal dialysis. Clin Nephrol. 2008;69(5): 368-372.

108. Penfield JG, Reilly RF Jr. What nephrologists need to know about gadolinium. Nat Clin Pract Nephrol. 2007;3(12): 654-668.

109. Weller A, Barber JL, Olsen OE. Gadolinium and nephrogenic systemic fibrosis: an update. Pediatr Nephrol. 2014;29(10):1927-1937.
110. Broome DR, Cottrell AC, Kanal E. Response to "Will dialysis prevent the development of nephrogenic systemic fibrosis after gadolinium-based contrast administration?" AJR Am J Roentgenol. 2007;189(4):W234-W125.

111. Nardone B, Saddleton E, Laumann AE, et al. Pediatric nephrogenic systemic fibrosis is rarely reported: a RADAR report. Pediatr Radiol. 2014;44(2):173-180.

112. Schwartz GJ, Munoz A, Schneider MF, et al. New equations to estimate GFR in children with CKD. J Am Soc Nephrol. 2009;20(3):629-637.

113. Schwartz GJ, Work DF. Measurement and estimation of GFR in children and adolescents. Clin J Am Soc Nephrol. 2009;4(11):1832-1843.

114. Filler G, Guerrero-Kanan R, Alvarez-Elias AC. Assessment of glomerular filtration rate in the neonate: is creatinine the best tool? Curr Opin Pediatr. 2016;28(2):173-179.

115. Abitbol CL, Seeherunvong W, Galarza MG, et al. Neonatal kidney size and function in preterm infants: what is a true estimate of glomerular filtration rate? $J$ Pediatr. 2014;164(5):1026-1031.e2.

116. Hoseini R, Otukesh H, Rahimzadeh N, Hoseini S. Glomerular function in neonates. Iran J Kidney Dis. 2012;6(3):166-172.

117. European Symposium on Urogenital Radiology. EUSUR Guidelines on Contrast Media. http://www.esur.org/guidelines/. Published 2012. Accessed October 25, 2017.

118. Altun E, Semelka RC, Cakit C. Nephrogenic systemic fibrosis and management of high-risk patients. Acad Radiol. 2009;16(7):897-905.

119. Martin DR, Krishnamoorthy SK, Kalb B, et al. Decreased incidence of NSF in patients on dialysis after changing gadolinium contrast-enhanced MRI protocols. J Magn Reson Imaging. 2010;31(2):440-446.

120. Shaffer KM, Parikh MR, Runge TM, Perez SD, Sakaria SS, Subramanian RM. Renal safety of intravenous gadoliniumenhanced magnetic resonance imaging in patients awaiting liver transplantation. Liver Transpl. 2015;21(11):1340-1346.

121. Nandwana SB, Moreno CC, Osipow MT, Sekhar A, Cox KL. Gadobenate dimeglumine administration and nephrogenic systemic fibrosis: is there a real risk in patients with impaired renal function? Radiology. 2015;276(3):741-747.

122. Janus N, Launay-Vacher V, Karie S, et al. Prevalence of nephrogenic systemic fibrosis in renal insufficiency patients: results of the FINEST study. Eur J Radiol. 2010;73(2):357-359.

123. Deray G, Rouviere O, Bacigalupo L, et al. Safety of meglumine gadoterate (Gd-DOTA)-enhanced MRI compared to unenhanced MRI in patients with chronic kidney disease (RESCUE study). Eur Radiol. 2013;23(5):1250-1259.

124. Amet S, Launay-Vacher V, Clement $\mathrm{O}$, et al. Incidence of nephrogenic systemic fibrosis in patients undergoing dialysis after contrast-enhanced magnetic resonance imaging with gadolinium-based contrast agents: the Prospective Fibrose Nephrogenique Systemique study. Invest Radiol. 2014;49(2):109-115.

125. Soyer P, Dohan A, Patkar D, Gottschalk A. Observational study on the safety profile of gadoterate meglumine in 35,499 patients: the SECURE study. J Magn Reson Imaging. 2017;45(4):988-997. 